CREATING SHARED VALUE AND JOB PERPERFORMANCE

Creating Shared Value (CSV) and Sport Employees' Job Performance: The Mediating

Effect of Work Engagement

May 2020

Word count: 7951 


\begin{abstract}
Research question: The salience of creating shared value (CSV) in innovating the process of social change has been acknowledged; however, we know little about CSV from views of employees who create shared value. This study examined how employees of a sport organization perceive their organization's CSV, and assessed the connections between employee CSV perception, vision integration, work engagement, and job performance.

Research methods: A new scale of employee CSV perception was validated using data from 207 employees within a sport organization in China. Structural equation modeling was performed, with a separate sample of 181 employees, to test the hypothesized relationships. The data were obtained through web-based questionnaires.

Results and findings: Employee CSV perception-formed as a second-order factor including sport, social, and economic values-was positively associated with vision integration.

Subsequently, vision integration had a positive relationship with in-role behavior (i.e., a measure of job performance), and this relationship was mediated by work engagement.

Implications: This study advances a theoretical understanding of CSV from the employees' perspective. Findings suggest that a sport organization can use CSV to increase employees' adoption of its vision, work engagement, and in-role behavior through team-building activities that facilitate employees' understanding of the vision.

KEYWORDS: Vision integration, In-role and extra-role behavior, Sport service, Corporate social responsibility, Social value
\end{abstract}


Creating Shared Value (CSV) and Sport Employees' Job Performance: The Mediating Effect of

\section{Work Engagement}

Understanding how sport organizations can benefit society has been an ongoing agenda in sport management (Babiak \& Wolfe, 2009; Hills et al., 2019; Walzel et al., 2018). Social responsibility initiatives have gained attention across different sectors of the sport industry, ranging from professional sport teams and leagues to sport apparel manufacturers (Anagnostopoulos et al., 2014; Lebrun et al., 2013). The development of social responsibility in the sport industry is worthy of praise; however, many social programs have lacked sufficient resources to deliver lasting social benefits, such as the enhancement of health in communities (Walker et al., 2017; Walzel et al., 2018). This issue has likely occurred because sport organizations' social programs have had weak connections with their core businesses. As such, scholars have called for an increased focus on understanding strategies that link sport organizations' social initiatives with core business objectives (Gerke et al., 2015; Hills et al., 2019; Walker \& Hills, 2017).

In the current study, we address this call by applying the concept of creating shared value (CSV; Porter \& Kramer, 2011). Building on the notion that social and economic values are equally important and complementary, CSV is defined as the creation of social value that simultaneously can produce economic value and vice versa (Dembek et al., 2016; Porter \& Kramer, 2011). For example, Adidas has partnered with an environmental organization to produce its sportswear from recycled ocean waste, which creates social value in the form of environmental protection, as well as economic value through revenue growth from the sale of the sportswear (Adidas, 2017). Consistent with the definition of CSV, this partnership would benefit society consistently so long as the revenue of selling the sportswear leads to further investment. 
The example of Adidas, as well as other preliminary evidence discussed in the literature (e.g., Hills et al., 2019; Walker \& Hills, 2017), suggests the salience of CSV in improving sport organizations' competitiveness.

Researchers have examined CSV from the perspective of corporate executives on how CSV may affect business success (Dembek et al., 2016; Maltz \& Schein, 2012); however, there is insufficient knowledge of how CSV functions from employees' viewpoint. An understanding of how employees perceive organizations' CSV and how this perception influences job performance is important because high performance among employees contributes to organizational goals (Du et al., 2015). Shared value cannot be created unless employees accept their organizations' vision and perform their job in a manner consistent with the vision. As a motivational construct, work engagement represents the degree of energy, emotion, and dedication employees have for their work (Bakker et al., 2008; Rich et al., 2010). Researching work engagement among sport employees is essential because, compared to other types of organizations, emotional and energetic characteristics are inextricably connected with job tasks performed within sport organizations (Swanson \& Kent, 2017).

The purpose of the current study is to examine how sport employees perceive their organization's CSV. In addition, the relationships between employee CSV perception, work engagement, and job performance are investigated. By linking employees' CSV perceptions to their job performance, the study will advance an understanding of how sport organizations could generate positive social outcomes and simultaneously sustain their economic benefits.

\section{Research Context}

CSV is still at its early stages of conceptual development, and it is important to gain insights on how CSV can be adopted in practice (Dembek et al., 2016). To illustrate how sport 
organizations can implement CSV, this study was conducted within a specific context, Nike+ Run Club of Greater China (hereafter NRCGC). As a multinational program run by Nike, Nike+ Run Club (NRC) has operations in many countries beyond China, such as Japan, the US, and the UK (NRC, n.d.). The international scope of the program will enable future researchers to consider how the findings of the current research may be applicable to similar programs in their countries. The remainder of this section explains how NRCGC helps Nike connect social and economic values through its services in promoting marathons.

NRCGC provides marathon training classes free of charge to residents in Chinese metropolitans, such as Beijing, Shanghai, and Guangzhou. Building on the connection between sport participation and the enhancement of health and well-being (Sato et al., 2015), NRCGC contributes to creating social value by inspiring people to run for fun and maintain a healthy lifestyle through running (NRC, n.d.). Participants can improve their health by maintaining a regular schedule of running (Sato et al., 2015). Because NRCGC gathers customers from all walks of life, the initiative may expand customers' social network by allowing them to interact with each other while participating. This shared experience may engender a sense of camaraderie (Green \& Chalip, 1998), promoting customers' engagement.

To leverage business opportunities, NRCGC incorporates multiple marketing activities into their operations. For example, the meeting place for each training session is set in a local Nike store, which may increase customers' exposure to Nike's brand and products. The increased exposure through frequent visits, in turn, may increase customers' likelihood of purchasing products (Sudhir \& Talukdar, 2004). Customers can also enjoy free trials of Nike's newest running shoes while attending classes. Research supports that a prior trial experience strengthens 
customers' product familiarity and evaluation, which promotes repetitive purchase behaviors (Wang et al., 2013).

These activities have enabled Nike to align social outcomes with economic outcomes, consistent with the proposition of CSV (Porter \& Kramer, 2011). The China Runners Annual Report points to the success of Nike in promoting marathons and healthy lifestyles (Iranshao, 2015, 2018). This report was based on survey data collected from approximately 10,000 individuals each year, with about two-thirds of the respondents being recruited from Beijing, Shanghai, and Guangzhou, where NRCGC operates. According to the report, the percentage of runners who ran at least three times a week increased by $20 \%$ between 2015 and 2018 . The increase in running frequency may enhance people's health and well-being. From the business side, respondents' self-reported expenses on running shoes increased from approximately $\$ 225$ to $\$ 303$ during the same years, and the percentage of those who prefer Nike over the other sport brands increased by $8.1 \%$ (Iranshao, 2015, 2018). Having established the research context, we now shift our focus to the conceptualization of employees' CSV perception.

\section{Literature Review}

\section{Differences between CSV and Corporate Social Responsibility (CSR)}

CSV refers to corporate strategies that "enhance the corporate competitiveness while simultaneously advancing the economic and social conditions in the communities in which it operates" (Porter \& Kramer, 2011, p. 66). CSV serves as a balance point where a corporation advances its competitiveness by fulfilling social needs and transferring the needs into a new point of revenue growth (Dembek et al., 2016; Schmitt \& Renken, 2012; Wójcik, 2016).

The idea of shared value is not new. Before the introduction of CSV by Porter and Kramer (2011), scholars have advanced similar concepts, especially CSR, which aims to address the 
relationship between business and society (Babiak \& Wolfe, 2009; McWilliams \& Siegel, 2001; Walzel et al., 2018). A review of literature suggests three major differences between CSV and CSR. Foremost, in the CSV model, fulfilling social needs is a part of business activities that has a direct association with economic value (Dembek et al., 2016; Wojcik, 2016). The primary motive for implementing CSV aligns with a corporation's economic interests and is internal. Conversely, CSR is regarded as a corporate response to external pressures from stakeholders, which may enhance its reputation (McWilliams \& Siegel, 2001; Wojcik, 2016). Thus, CSR has an indirect association with economic growth via corporate reputation.

Second, according to CSV, social and economic values are equally important and the creation of one value should not sacrifice the other. Value can be shared by expanding the total value created. Corporations should sustain their investment in a certain social initiative as long as it is profitable (Porter \& Kramer, 2011). In contrast, CSR emphasizes the importance of social value over economic value (Wojcik, 2016). It works under a rationale of value redistribution, where social value is often created at the expense of corporate interests (Dembek et al., 2016). Although corporations embrace CSR when their economic situation is stable, CSR is vulnerable when they suffer from economic downturn.

Third, from an employee perspective, CSR practices are encouraged by corporations, but these activities are considered discretionary behaviors that have little connection with official requirements (Korschun et al., 2014; Slack et al., 2015). Hence, employees may not be fully aware of an organizations' CSR; or they may not feel engaged if CSR does not serve their selfinterests (Slack et al., 2015). Unlike CSR, CSV is a part of core business activities, and employees' contribution to achieving a company's social goal is reflected in their performance 
appraisals (Dembek et al., 2016; Wojcik, 2016). Thus, employees would be engaged in prosocial behaviors as part of their job responsibilities (Slack et al., 2015).

\section{CSV of Sport Organizations}

To assess the effectiveness of sport organization's capacity to generate social impact, some scholars have explored the application of CSV in sport contexts. For example, Hills et al. (2019) examined a professional sport league's CSV program designed to increase children's health through sport promotion in the UK. The authors posited that CSV could sustain a sport organization's engagement in social changes by facilitating their business achievements. By assessing the effects of the program through a mixed-methods approach, Hills et al. found that participants generated high levels of identification with, and affinity towards, the league and its sport, which contributed to the expansion of the league's market. In terms of social outcomes, their analysis did not find strong evidence for the program's impact on health promotion; however, the authors contend that the league would continue implementing the program because of its business value (Hills et al., 2019). Furthermore, Gerke et al. (2015) illustrated CSV in sport with an example of how sailing manufacturers increased their competitiveness by promoting the development of local communities in France. Through the case analysis, the authors demonstrated that sport organizations could increase their business performance by investing in and shaping their local communities. Similarly, Heinze, Soderstrom, and Zdroik (2014) studied the process of cluster development (i.e., one way of implementing CSV as suggested by Porter and Kramer [2011]) using a case of a US professional sport team. Their findings highlighted the importance of matching community needs with an organization's resources for shared value creation in practice (Heinze et al., 2014). Overall, these studies demonstrated that CSV has been 
applied to sport organizations, offering contextual support for the importance of investigating CSV perception among sport employees.

\section{Conceptualization of CSV Perception}

The CSV literature has developed Porter and Kramer's (2011) initial concept to a multidimensional, value-oriented construct (Corazza et al., 2017; Schmitt \& Renken, 2012). By interviewing 11 companies' executives, Schmitt and Renken (2012) proposed three dimensions of CSV: social value, economic value, and value of a corporation's core business. The integration of the three values can direct a company's business activities for CSV. Similarly, based on a review of 29 multinational companies' CSV reports, Corazza et al. (2017) found CSV is a grand concept blending "stakeholders' needs, societal development, and business competitiveness" (p. 431). Stakeholders' needs represent pressing requirements of customers or communities that are relevant to business success. Societal development refers to the achievement of common goods (e.g., community well-being). Business competitiveness includes revenue increases. The integration of the three elements is critical for successfully planning CSV and observing the shared value in reality (Corazza et al., 2017).

Consistent with the above conceptualizations (Corazza et al., 2017; Schmitt \& Renken, 2012), Dolles et al. (2014) demonstrated that shared value generated by sport-related business may include social value, economic value, and the value of sport development (hereafter 'sport value'). Sport value refers to encouraging sport participation and improving the quality of sport performance (Shilbury et al., 2008). In the current research, we propose that sport employees' CSV perception refers to the degree to which they perceive that their organization adopts a strategy of creating three types of value simultaneously: (a) sport value, (b) social value, and (c) economic value. 


\section{Hypotheses Development}

To guide the current study, a theoretical framework (see Figure 1) is established to advance an understanding of how sport employees' CSV perception is associated with their vision integration, work engagement, and job performance.

[Insert Figure 1 around here]

\section{CSV Perception and Vision Integration}

CSV is an innovative corporate strategy that expands the overall value created through business activities (Porter \& Kramer, 2011). Like any other innovative objective applied to an organizational setting, translating the knowledge of CSV into employee productivity takes time and effort. Failures in the adoption of innovative strategies occur because of employees' heterogeneity, where employees have different understandings of their organizations' goals depending on their specific economic and developmental expectations (Du et al., 2015). A lack of common understanding of an innovative strategy will distract employees from performing their assigned tasks to achieve their organization's goals. This issue may be challenging for CSV, which integrates multiple goals relating to different values.

For an organization to achieve its goals, it is critical to promote employees' engagement in the organization's vision (Carsten \& Bligh, 2008; Rich et al., 2010). Vision integration was proposed to address the distractive issue of employees' heterogeneity and enhance desirable outcomes (Carsten \& Bligh, 2008; Kohles et al., 2013). Vision integration refers to the extent to which employees choose to adopt an organization's vision as a guide to conduct daily work (Kohles et al., 2013). A vision is a set of images demonstrating an organization's goals and future (Christenson \& Walker, 2004). Employees' perceptions of novelty and the significance of 
their work increase the adoption and integration of an organization's vision into their work behaviors (Carsten \& Bligh, 2008; Haslam \& Platow, 2001; Kohles et al., 2013).

In the context of NRCGC, most employees are advanced runners. Running is an important part of their personal lives. By providing marathon training to communities, NRCGC employees contribute to promoting running as a preferred sport for leisure, creating sport value, and improving health conditions in society, which can be regarded as the vision of NRCGC. Meanwhile, through associated marketing activities, NRCGC employees increase the exposure of Nike among customers, and economic value is created. The perceived contributions to personal lives, society, and the organization may lead employees to regard their job as meaningful and significant, which increases the possibility of vision integration (Carton \& Lucas, 2018; Kihles et al., 2013). Thus, it is proposed:

H1. CSV perception has a positive association with vision integration.

Job performance refers to a set of behaviors that employees enact to achieve organizational goals (Rich et al., 2010). Because of the complex and dynamic nature of organizational goals, employees often do more than officially required to accomplish their tasks (Bienstock, DeMoranville, \& Smith, 2003; Christian et al., 2011). Consequently, job performance consists of two dimensions: in-role and extra-role behavior (Bakker \& Leiter, 2010; Rich et al., 2010). Inrole behavior refers to formally required behaviors directed to achieving an organization's goals (Rich et al., 2010). Extra-role behavior includes discretionary behaviors that promote effectiveness in goal achievement beyond the official requirements. Researchers postulated the link between employees' vision integration and in-role behavior (Haslam \& Platow, 2001; Kohles et al., 2013). The promotion of a vision allows an organization to create an ideal employee image associated with the vision, which increases employees' performance (Haslam \& 
Platow, 2001). Hence, we posit that a shared vision between employees and their organizations helps communicate what is expected for work roles, promoting in-role behavior. Conversely, extra-role behavior is an attitude-oriented and discretionary action not required by organizations (Kohles et al., 2013; Rich et al., 2010; Slack et al., 2015). Because of the voluntary nature of extra-role behavior, it may not be influenced by vision integration. Consequently, we hypothesize that the integration of NRCGC's vision promotes employee in-role behavior only.

H2. Vision integration has a positive association with in-role behavior.

\section{Work Engagement and Job Performance}

Work engagement is defined as "a positive, fulfilling, affective-motivational state of work related well-being” (Bakker et al., 2008, p. 187). Engaged employees tend to find their job meaningful, interesting, and attractive, and hence exhibit enthusiasm and happiness (Bakker \& Leiter, 2010; Grant et al., 2007; Schaufeli et al., 2008). Determinants of work engagement are well-documented (Bakker \& Leiter, 2010; Christian et al., 2011; Carton \& Lucas, 2018). For example, Carton and Lucas (2018) proposed that when employees perceive that their organizations value behaviors which are personally important to them, employees are likely to find their work meaningful and enjoyable. In turn, the positive perceptions increase work engagement. This notion implies that congruence between employees' and organizations' expectations or values may increase work engagement. Because an organization's vision serves as an important representation of its goals and values (Carton \& Lucas, 2018; Kohles et al., 2013), employees may become engaged when they adopt organizational vision. As predicted in H1, NRCGC employees' CSV perception may encourage them to adopt their organization's vision. The process of vision integration may result in a congruence between NRCGC and its employees, strengthening work engagement. This logic leads to the following hypothesis: 
H3. Vision integration has a positive association with work engagement.

Highly engaged employees are more energetic, enthusiastic, and dedicated to their tasks and workplaces, and these feelings can incite more effort to accomplish their tasks (Christian et al., 2011; Schaufeli et al., 2008). However, due to diverse categorizations of job performance, previous studies indicated mixed results between work engagement and job performance (Christian et al., 2011; Rich et al., 2010; Xanthopoulou et al., 2009). The current study addresses this ambiguity by examining NRCGC employees' in-role and extra-role behaviors as two outcomes of work engagement.

With respect to in-role behavior, highly engaged employees may be more concentrated on meeting organizational expectations than their less engaged counterparts because of the high positive emotions they experience at the workplace. According to the broaden-and-build theory (Fredrickson, 2001), employees' positive emotion will motivate them to acquire new information in the workplace, and the accumulation of the information will enable them to develop personal resources, such as knowledge and skills. In turn, personal development strengthens employees' capacity to meet their organizations' expectations over time (Bakker et al., 2008; Fredrickson, 2001; Rich et al., 2010), leading to superior performance of in-role behavior. For NRCGC employees, their work engagement may increase their motivation for learning new information related to the program, which will guide them toward the development of personal resources that are instrumental in meeting the organization's expectations regarding their job. Thus, we hypothesize:

H4. Work engagement has a positive association with in-role behavior.

With respect to extra-role behavior, although this type of behavior may not directly contribute to achieving organizations' goals, it can facilitate employees' effectiveness by 
forming an inclusive and supportive environment (Bakker et al., 2008; Rich et al., 2010). This notion is supported by the presence of implicit reciprocity in the workplace (Christian et al., 2011; Slack et al., 2015; Xanthopoulou et al., 2009). That is, employees who are highly engaged in their jobs will feel happy and energetic at work. To maintain this enjoyment, engaged employees are motivated to put forth extra efforts, such as helping colleagues, continuing to learn, and maintaining friendly relationships with customers, that can enhance their work accomplishments as an exchange (Bakker \& Leiter, 2010; Christian et al., 2011; Rich et al., 2010). In the current context, if NRCGC employees feel engaged in their work, they are more willing to invest additional effort when interacting with program participants. For example, along with providing the professional training required by NRCGC, engaged employees may have informal conversations with participants to reduce the anxiety associated with running training. Our next hypothesis is as follows:

\section{H5. Work engagement has a positive association with extra-role behavior.}

Scholars have found preliminary evidence of the link between vision integration and job performance (Haslam \& Platow, 2001; Kohles et al., 2013). However, their examinations of only direct associations explained a small amount of the variance in job performance, which implies the presence of a mediator within the relationship between vision integration and job performance. Given the hypothesized effect of vision integration on work engagement (H3) and the effect of work engagement on in-role (H4) and extra-role (H5) behaviors, we postulate that work engagement, as a mediator, may establish the relationship between vision integration and each of the two dimensions of job performance. These hypothesized mediating effects are consistent with prior research indicating that managerial activities, such as inspiring employees with an optimistic future and emphasizing a collective vision, would improve workplace well- 
being while promoting job performances (Carsten, \& Bligh, 2008; Carton \& Lucas, 2018; Rich et al., 2010). In the current research, NRCGC employees' vision integration facilitates a collective vision for the organization's goals and future. Employees are clear and optimistic about their work, improving work engagement which promotes in-role and extra-role behaviors. Hence, work engagement is hypothesized to mediate the relationships between vision integration and in-role and extra-role behaviors.

H6. Work engagement mediates the relationship between vision integration and in-role behavior.

H7. Work engagement mediates the relationship between vision integration and extra-role behavior.

\section{Methods}

\section{Participants and Data Collection}

The population of this study was employees of NRCGC who serve as coaches and pacers in marathon training and directly interact with program participants. A focus on this population is appropriate because their perceptions of CSV and work performance are central to the success of NRCGC. A survey design was used to collect data from the five branches of NRCGC: Beijing, Shanghai, Guangzhou, Hong Kong, and Taipei. The total number of potential respondents was 240. In March 2018, an e-mail invitation that contained a cover letter describing the purpose of the study and a link to an online questionnaire was sent to each NRCGC employee. After a follow-up e-mail, 181 respondents $(75.5 \%)$ completed the survey.

To address the concern of nonresponse error (Jordan et al., 2011), we compared demographics of the respondents with those of the population. Among the 181 respondents, 26.6\% were recruited from Beijing, 23.6\% from Shanghai, 16.3\% from Guangzhou, 18.2\% from 
Hong Kong, and $15.2 \%$ from Taipei. Additionally, $62.6 \%$ of the respondents were male. The mean age was 29 years old $(S D=5.23)$ and $60.5 \%$ of respondents had participated in running for at least 4 years. In comparing the sample to the population, the first author obtained population demographics from the organization. Twenty-five percent of the population is based in Beijing, $23.1 \%$ in Shanghai, $17 \%$ in Guangzhou, $19.3 \%$ in Hong Kong, and $14.8 \%$ in Taipei. This population has a mean age of 28 years old and $65.8 \%$ are male. Fifty-nine percent of NRCGC employees have participated in marathons for at least four years. These statistics suggest that our sample represented the population, alleviating the concern of nonresponse error (Jordan et al., 2011).

\section{Measurements}

We used items with a 7-point Likert scale (i.e., from 1 as "never" to 7 as "always") to measure vision integration, work engagement, in- and extra-role behavior, and CSV perception. Vision integration was measured using Kohles et al.'s (2013) 5-item scale of vision integration, which was shown to be reliable $(\alpha=.95)$. We measured work engagement using Schaufeli et al.'s (2008) Utrecht Work Engagement Scale, which provided adequate reliability $(\alpha=.88)$ in Allen and Bartle's (2014) study of sport volunteers. In-role and extra-role behaviors were measured with a six-item self-rating scale developed by Bienstock et al. (2003). We replaced "company" with "NRCGC" or "NRCGC courses" and "consumer" with "runner" to adapt to the current research context.

Because data were collected in China, we originally designed the survey in English and then translated it into Chinese. Following the back-translation technique used by Doherty, Chen, and Alexander (2014), all survey items were translated into Chinese by the first author who is a native speaker. Next, the Chinese survey was independently translated back to English by a 
doctoral student who is another native speaker and majors in English as a second language.

Subsequently, the equivalency of the original and back-translated English surveys was verified by a third doctoral student who is a native English speaker. For items that were identified as inequivalent, the first author engaged in discussion with the two doctoral students to reach consensus for modification.

\section{Development of the Scale of Employee CSV Perception}

Because there were no existing measures of CSV perception, we created a scale for the current study (DeVellis, 2016). In-depth interviews were first conducted with ten senior coaches and pacers (six males and four females). The interviewees had worked with NRCGC for at least two years. The interviews concentrated on understanding the interviewees' perceptions of the efficacy and impacts of NRCGC and lasted approximately 40 minutes each. Sample questions included "Are you aware of any contributions [or value] to your company and society, produced by your service?" and "What do you think of NRCGC? Is it a social program, a marketing strategy, or anything else?" The interviews were professionally transcribed and translated into English, and then the first author analyzed the transcripts using the open coding and axial coding process (Creswell \& Miller, 2000). The coded information was synthesized and grouped into the three dimensions of CSV perception, as shown in Table 1. Twenty items were then generated using interviewees' statements.

To refine and validate the scale, the 20 items, along with the definition of CSV perception, were sent to an external expert panel, comprising two faculty members and three doctoral students in sport management and human resources development. The experts evaluated the content validity and clarity of the items (DeVellis, 2016). Modifications were made based on the experts' suggestions. For example, an item "People are healthier after running with us" was 
eliminated because health status is difficult to assess subjectively. Finally, nine items were retained to measure employees' CSV perception, and were assessed in a scale validation study.

In this validation study, the nine-item scale of employee CSV perception was administered to a sample of 207 employees (e.g., support staff of NRCGC, salespersons in retail stores used as the meeting place for NRCGC training) who worked in the cities where NRCGC operates and had knowledge about the program. Of the 207 respondents, $69 \%$ were female, the mean age was 32 years old $(S D=7.71)$, and $43.6 \%$ had worked in their current positions for at least two years.

To identify the factor structure of employee CSV perception, an exploratory factor analysis (EFA) was performed with the sample $(N=207)$ using principal axis factoring with oblique rotation. The Kaiser-Meyer-Olkin measure of sampling adequacy was .86, suggesting an acceptable degree of common variance (Hair, Black, Babin, Anderson, \& Tatham, 2010). The Bartlett's Test of Sphericity was $1513.45(p<.001)$, indicating an adequate correlation matrix for EFA. The EFA results (see Table 2) indicated the extraction of three factors (which correspond to our conceptualization of sport, social, and economic values) with an eigenvalue greater than 1 . These factors together accounted for $76.5 \%$ of the total variance. The internal consistency of the scale was assessed by Cronbach's alpha scores. Table 2 reported that the Cronbach's alpha of the factors ranged from .75 to .89, indicating acceptable reliability (Kline \& Moosbrugger, 2000). The three-factor structure, as well as the scale reliability and validity, was further assessed with the full measurement model using data collected for the main study (see the Results section).

[Insert Table 2 around here]

\section{Data Analysis}

Before performing structural equation modeling (SEM) with maximum likelihood estimation, we conducted the Skewness-Kurtosis test for multivariate normality of all variables 
using SPSS 26.0. Skewness values exceeding an absolute value of 2.00 and kurtosis values exceeding an absolute value of 7.00 indicate the violation of the assumption of normal distribution (Bandalos, 2002).

After checking the multivariate normality, SEM was used to examine the hypotheses. Following Anderson and Gerbing's (1988) procedures, a measurement model was first tested by a confirmatory factor analysis (CFA) using the Mplus 7.4 statistical package. A structural model was then developed to assess the hypothesized relationships.

The overall model fit was examined based on the goodness-of-fit indices (Hu \& Bentler, 1999). A cutoff value of .95 for Comparative Fit Index (CFI), .08 for Standardized Root Mean Square Residual (SRMR), and .06 for Root Mean Square Error of Approximation (RMSEA) suggest a good model fit. The standard factor loading exceeding .60 (Hair et al., 2010), average variance extracted (AVE) values above .50 , construct reliability $(\mathrm{CR})$ values greater than .70 (Fornell \& Larcker, 1981), and the heterotrait-monotrait (HTMT) ratios smaller than .85 (Hair et al., 2010) support the reliability and validity of the scales examined.

According to the recommended mediation analysis (Hair et al., 2010), the examination of work engagement as a mediator was to assess whether an indirect effect, specifically the product of the path from vision integration to work engagement and the path from work engagement to in-role (or extra-role) behavior, would be statistically significant. We employed a nonparametric, bootstrapping procedure with 5000 incidences of re-sampling to calculate a bias-corrected $95 \%$ confidence interval (CI) for the indirect effect. The indirect effect is identified if the 95\% CI excludes zero (Hair et al., 2010).

\section{Results}

\section{Testing of Data Normality}


All values of Skewness-Kurtosis tests were below the recommended thresholds (Bandalos, 2002). The skewness values ranged from -1.82 to -.46 , and the kurtosis values were between -.26 and 6.46. These results indicated that the abnormal distributions of each variable were not of significant magnitude to affect the results of SEM (Bandalos, 2002).

\section{Testing of the Measurement Model}

The CFA results indicated that the measurement model yielded a good model fit $\left(\chi^{2} / d f=\right.$ 1.64; CFI $=.95 ; \mathrm{RMSEA}=.07 ; \mathrm{SRMR}=.06)$. Table 3 showed that all the factor loadings met the recommended threshold. All the constructs had AVE values above .50 and CR values above .70 . These results supported the construct reliability and convergent validity of the multiitem scales. Discriminant validity was supported by the results provided in Table 4 indicating that the AVE values were greater than squared correlation coefficients between any pair of the constructs, while all of the HTMT ratios were smaller than .85 .

[Insert Table 3 around here]

[Insert Table 4 around here]

\section{Determining the Factor Structure of CSV Perception}

We posited employee CSV perception as a second-order factor for two reasons. Foremost, because the creation of shared value is achieved simultaneously by integrating multiple values into a single strategy (Porter \& Kramer, 2011), high inter-correlations among the three values are expected, and the second-order factor structure is appropriate for handling the multicollinearity issue within the dimensions (Koufteros et al., 2009). Moreover, the second-order factor corresponds to our research purpose, which is to investigate how employees' CSV perception, as a global concept, influences job performance. 
To confirm the appropriateness of the second-order factor model (M4), we compared M4 with three alternative models (Koufteros et al., 2009): a single-factor model (M1), a three-factor uncorrelated model (M2), and a three-factor correlated model (M3). Table 5 showed that goodness-of-fit indices for M1 and M2 were unacceptable, whereas indices for M3 and M4 were adequate and similar. Of the latter two models, M4 is preferred because it is more parsimonious (Koufteros et al., 2009; Tanriverdi, 2006). Additionally, the standard factor loadings of sport value, social value, and economic value on CSV perception in the second-order factor model are large and significant, supporting the adoption of a higher-order construct (Tanriverdi, 2006). The Target coefficient, defined as the ratio of the chi-square values between the first-order and second-order models, was .98 , indicating that the second-order factor fully captures the relationships of the first-order factors (Tanriverdi, 2006). Collectively, these results supported our specification of CSV perception as a second-order factor consisting of the three first-order factors.

\section{[Insert Table 5 around here]}

\section{Testing of the Structural Model}

The SEM yielded the following results of the goodness-of-fit indices for the structural model: $\chi^{2} / d f=1.74, \mathrm{CFI}=.92, \mathrm{RMSEA}=.07$, and SRMR $=.07$. Although some of the values do not meet the recommended criteria, the indices as a whole suggest a sufficient model fit (Hu \& Bentler, 1999). As shown in Figure 2, CSV perception had a significant positive association with vision integration $(\beta=.74, p<.01)$, which in turn positively predicted in-role behavior $(\beta=.32, p<.01)$. These results confirmed $\mathrm{H} 1$ and $\mathrm{H} 2$. Vision integration was also positively associated with work engagement $(\beta=.55, p<.01)$, as predicted by H3. Regarding the outcomes of work engagement, in support of $\mathrm{H} 4$, work engagement was positively associated 
with in-role behavior $(\beta=.20, p=.03)$. Conversely, the association between work engagement and extra-role behavior was nonsignificant $(\beta=.13, p=.10)$; H5 was not supported.

[Insert Figure 2 around here]

\section{Testing of the Mediating Effect}

The relationship between vision integration and in-role behavior was significantly mediated by work engagement $(\beta=.11, \mathrm{CI}=[.10, .30])$, providing support for H6. However, the indirect effect of work engagement on the relationship between vision integration and extra-role behavior was not significant $(\beta=.07, \mathrm{CI}=[-.02, .22])$; these results disconfirmed $\mathrm{H} 7$.

\section{Discussion}

The results showed that a positive relationship between employee CSV perception and inrole behavior was established through vision integration and work engagement. These associations imply that CSV perception contributes to employees' work engagement when they are willing to adopt an organizational vision (i.e., vision integration). The positive connection between work engagement and in-role behavior indicates that the promotion of employees' workplace well-being may increase their devotion to behaviors desired by their organizations.

In contrast, the nonsignificant relationship between employee work engagement and extrarole behavior suggests that even when NRCGC employees are highly engaged in their work, they may not devote additional efforts to the work not specified in their job descriptions. Although this finding contradicts our hypothesis, it may be explained by the characteristics of the current research context, where CSV directs employees' behaviors for both social and economic outcomes (Schmitt \& Renken, 2012). When their organization does not implement CSV, employees may think that behaviors toward economic outcomes are in-role behavior while those toward social outcomes are extra-role behavior (Vigoda-Gadot, 2007). However, an 
organization's CSV activities may be complex and require employees to invest additional efforts in their work, even if the activities are not officially stated. Thus, employees may regard some of their extra-role behaviors, which are compulsory (or informally required), as a part of in-role behavior.

\section{Theoretical Implications}

This study contributes to an understanding of CSV from employees' perspectives. Because CSV represents an innovative business strategy that appeals to corporations, it is important to understand employees' responses that support CSV implementation in practice. The current study examined how employees perceive their organizations' CSV as well as how this perception is associated with their job performance. Our research expands the scope of the CSV literature by conducting an analysis at the individual employee level and by revealing that employees' CSV perception positively influences their in-role behavior through the promotion of their value integration and work engagement. The current results support the theoretical proposition that CSV can enhance workforce productivity in an organizations' value chain (Porter \& Kramer, 2011).

Nike's CSV supports Hills et al.’s (2019) finding that shared value may be achieved by promoting sport participation. Building on the connections between running participation, health enhancement, and sport consumption, the current research illustrates how a sport organization creates economic value (i.e., driving sales of running shoes) through the creation of sport and social value (i.e., encouraging running participation for health and well-being). The significant indirect relationship between CSV perception and employees' in-role behavior suggests that employees may become productive and excel in their assigned tasks by positively perceiving their organization's CSV. This relationship empirically supports the proposition drawn from 
Porter and Kramer's (2011) work that CSV would improve productivity in the value chain, which adds to the sport management literature and reinforces the applicability of CSV in sport.

Building on the conceptualizations of CSV (Corazza et al., 2017; Schmitt \& Renken, 2012), the current research operationalized employee CSV perception as a second-order factor consisting of sport value, social value, and economic value. The identification of sport value as one primary component of CSV in a sport setting enriches the meaning of CSV beyond merely creating social and economic values. The identification of sport value may represent a distinctive type of value that rests on the uniqueness of the sport domain. The finding supports the necessity of "building a sport-focused research agenda" (Chalip, 2006, p.15) in the sport management discipline, offering an initial insight into the understanding of CSV in sport.

Furthermore, identifying specific value of an organization's CSV helps answer the question of "what constitutes shared value?" (Dembek et al., 2016, p. 237). In their review, Dembek et al. (2016) highlighted one critical issue within the existing CSV research; that is, it ignored the premise of fulfilling social needs by merely following Porter and Kramer's (2011) three propositions of CSV implementation, including reconceiving products and markets, redefining productivity, and bolstering clutter development. This is problematic because the creation of shared value occurs only when a company makes concerted efforts to balance the needs of business and society, beyond just adopting certain propositions (Maltz \& Schein, 2012). Our research suggests that identifying the specific value that meets the needs of companies and stakeholders is the first step towards the achievement of shared value.

\section{Managerial Implications}

Our findings indicate a link between an organization's deployment of CSV and employees' improved performance through vision integration. Meanwhile, organizations may face 
challenges in cultivating this link because delivering an abstract vision to employees is difficult. Drawing on the vision communication perspective (Carton \& Lucas, 2018), we suggest the following strategies for sport managers to facilitate vision integration. The first strategy is to use image-based prescription that translates the vision with specific actions, events, and other visual representations (Carton \& Lucas, 2018). Managers can split the vision into a few smaller phrases and conduct training activities or workshops where employees can observe and discuss these aspects of the vision. For example, in the case of NRCGC, employees (i.e., pacers) participated in seasonal internal training sessions. In these sessions, pacers were engaged in role-playing activities, where they acted as customers who observed and received services from their leaders (i.e., coaches). In turn, coaches played the role of pacers and demonstrated exemplary visionbased behaviors when serving customers. After the sessions, the pacers shared their reflections on how the coaches' behaviors aligned with the organization's vision. Through the activities, employees were able to directly observe and understand what and how to meet their organization's expectations.

A second strategy is to involve employees in vision creation (Carton \& Lucas, 2018; Kohles et al., 2013). Employees, as key stakeholders, have important and creative ideas about what their organization may look like in the future. Enabling employees' participation in the creation of a vision can align their personal goals with the organization's vision and increases the possibility that the vision is accepted by them (Kohles et al., 2013). Managers could drive vision integration by facilitating employees' participation through team building activities and daily conversations while encouraging employees to provide suggestions for improving the vision. When employees identify an alignment between the organization's vision and their personal goals, they are mobilized to act in adherence to organization's vision (Carton \& Lucas, 2018). 
Through these strategies, managers can motivate employees to integrate the organization's vision, be involved in the process of CSV, and exert efforts to produce outcomes desired by their organizations.

\section{Limitations and Future Research}

The current research has limitations. Foremost, the framework may have limited generalizability because it was examined using NRCGC as a specific case. This issue could be solved by testing the framework in other sport contexts where CSV is implemented, such as the National Football League (Heinze et al., 2014).

Second, this study specified CSV perception with three dimensions: sport value, social value, and economic value. This specification may not be directly used in other cases where organizations place emphasis on different values constituting CSV. To advance our understanding of CSV, future research can explore the influence of CSV perception from the perspective of other stakeholders such as customers (Dembek et al., 2016). For example, a qualitative study may be developed to compare customers' perspectives with our findings of employees' CSV perception. In this future research, interviews could be conducted with customers to explore how their perceptions of CSV differ from the vision and values the organization and its employees intend to communicate. 


\section{References}

Adidas. (2017). Sustainability progress report. https://www.adidasgroup.com/en/sustainability/reporting/sustainability-reports.

Allen, J. B., \& Bartle, M. (2014). Sport event volunteers' engagement: management matters. Managing Leisure, 19(1), 36-50. https://doi.org/10.1080/13606719.2013.849502

Anagnostopoulos, C., Byers, T., \& Shilbury, D. (2014). Corporate social responsibility in professional team sport organisations: Towards a theory of decision-making. European Sport Management Quarterly, 14(3), 259-281.

https://doi.org/10.1080/16184742.2014.897736

Anderson, J. C., \& Gerbing, D. W. (1988). Structural equation modeling in practice: A review and recommended two-step approach. Psychological Bulletin, 103(3), 411-423.

Babiak, K., \& Wolfe, R. (2009). Determinants of corporate social responsibility in professional sport: Internal and external factors. Journal of Sport Management, 23(6), 717-742. https://doi.org/10.1123/jsm.23.6.717

Bakker, A. B., \& Leiter, M. P. (2010). Work engagement: A handbook of essential theory and research. Psychology Press.

Bakker, A. B., Schaufeli, W. B., Leiter, M. P., \& Taris, T. W. (2008). Work engagement: An emerging concept in occupational health psychology. Work \& Stress, 22(3), 187-200. https://doi.org/10.1080/02678370802393649

Bandalos, D. L. (2002). The effects of item parceling on goodness-of-fit and parameter estimate bias in structural equation modeling. Structural Equation Modeling, 9(1), 78-102. https://doi.org/10.1207/S15328007SEM0901_5 
Bienstock, C. C., DeMoranville, C. W., \& Smith, R. K. (2003). Organizational citizenship behavior and service quality. Journal of Services Marketing, 17(4), 357-378. https://doi.org/10.1108/08876040310482775

Carsten, M. K., \& Bligh, M. C. (2008). Lead, follow, and get out of the way: Involving employees in the visioning process. In R. E. Riggio, I. Chaleff, \& J. Lipman-Blumen (Eds.), The Warren Bennis signature series. The art of followership: How great followers create great leaders and organizations (pp. 277-290). Jossey-Bass.

Carton, A. M., \& Lucas, B. J. (2018). How can leaders overcome the blurry vision bias? Identifying an antidote to the paradox of vision communication. Academy of Management Journal, 61(6), 2106-2129. https://doi.org/10.5465/amj.2015.0375

Chalip, L. (2006). Toward a distinctive sport management discipline. Journal of Sport Management, 20(1), 1-21. https://doi.org/10.1123/jsm.20.1.1

Christenson, D., \& Walker, D. H. (2004). Understanding the role of "vision" in project success. Project Management Journal, 35(3), 39-52. https://doi.org/10.1177/875697280403500306

Christian, M. S., Garza, A. S., \& Slaughter, J. E. (2011). Work engagement: A quantitative review and test of its relations with task and contextual performance. Personnel Psychology, 64(1), 89-136. https://doi.org/10.1111/j.1744-6570.2010.01203.x

Corazza, L., Scagnelli, S. D., \& Mio, C. (2017). Simulacra and sustainability disclosure: Analysis of the interpretative models of creating shared value. Corporate Social Responsibility and Environmental Management, 24(5), 414-434.

https://doi.org/10.1002/csr.1417 
Creswell, J. W., \& Miller, D. L. (2000). Determining validity in qualitative inquiry. Theory into Practice, 39(3), 124-130. http://doi.org/10.1207/s15430421tip3903_2

Dembek, K., Singh, P., \& Bhakoo, V. (2016). Literature review of shared value: A theoretical concept or a management buzzword? Journal of Business Ethics, 137(2), 231-267.

DeVellis, R. F. (2016). Scale development: Theory and applications. SAGE

Doherty, A. M., Chen, X., \& Alexander, N. (2014). The franchise relationship in China: Agency and institutional theory perspectives. European Journal of Marketing, 48(9/10), 16641689. https://doi.org/10.1108/EJM-04-2012-0199

Dolles, H., Soderman, S., Morgan, A., Adair, D., Taylor, T., \& Hermens, A. (2014). Sport sponsorship alliances: Relationship management for shared value. Sport, Business and Management: An International Journal, 4(4), 270-283. https://doi.org/10.1108/SBM-12$\underline{2013-0044}$

Du, S., Bhattacharya, C. B., \& Sen, S. (2015). Corporate social responsibility, multi-faceted jobproducts, and employee outcomes. Journal of Business Ethics, 131(2), 319-335. https://doi.org/10.1007/s10551-014-2286-5

Fornell, C., \& Larcker, D. F. (1981). Evaluating structural equation models with unobservable variables and measurement error. Journal of Marketing Research, 18(1), 39-50. https://doi.org/10.1177/002224378101800104

Fredrickson, B. L. (2001). The role of positive emotions in positive psychology: The broadenand-build theory of positive emotions. American Psychologist, 56(3), 218-226. https://doi.org/10.1037/0003-066X.56.3.218 
Gerke, A., Desbordes, M., \& Dickson, G. (2015). Towards a sport cluster model: the ocean racing cluster in Brittany. European Sport Management Quarterly, 15(3), 343-363. https://doi.org/10.1080/16184742.2015.1019535

Grant, A. M., Christianson, M. K., \& Price, R. H. (2007). Happiness, health, or relationships? Managerial practices and employee well-being tradeoffs. Academy of Management Perspectives, 21(3), 51-63. https://doi.org/10.5465/amp.2007.26421238

Green, B. C., \& Chalip, L. (1998). Sport tourism as the celebration of subculture. Annals of Tourism Research, 25(2), 275-291. https://doi.org/10.1016/S0160-7383(97)00073-X

Hair, J. F., Black, W. C., Babin, B. J., Anderson, R. E., \& Tatham, R. L. (2010). Multivariate data analysis. Pearson Prentice Hall.

Haslam, S. A., \& Platow, M. J. (2001). The link between leadership and followership: How affirming social identity translates vision into action. Personality and Social Psychology Bulletin, 27(11), 1469-1479. https://doi.org/10.1177/01461672012711008

Heinze, K. L., Soderstrom, S., \& Zdroik, J. (2014). Toward strategic and authentic corporate social responsibility in professional sport: A case study of the Detroit Lions. Journal of Sport Management, 28(6), 672-686. https://doi.org/10.1123/JSM.2013-0307

Hills, S., Walker, M., \& Barry, A. E. (2019). Sport as a vehicle for health promotion: A shared value example of corporate social responsibility. Sport Management Review, 22(1), 126141. https://doi.org/10.1016/j.smr.2018.10.001

Hu, L., \& Bentler, P. M. (1999). Cutoff criteria for fit indexes in covariance structure analysis: Conventional criteria versus new alternatives. Structural Equation Modeling: A Multidisciplinary Journal, 6(1), 1-55. https://doi.org/10.1080/10705519909540118

Iranshao. (2015). China runner annual report. https://iranshao.com/articles/2553-runner-report. 
Iranshao. (2018). China runner annual report. https://iranshao.com/articles/5410-summaryinformation-of-runner-report-2018.

Jordan, J. S., Walker, M., Kent, A., \& Inoue, Y. (2011). The frequency of nonresponse analyses in the Journal of Sport Management. Journal of Sport Management, 25(3), 229-239. https://doi.org/10.1123/jsm.25.3.229

Klein, A., \& Moosbrugger, H. (2000). Maximum likelihood estimation of latent interaction effects with the LMS method. Psychometrika, 65(4), 457-474. https://doi.org/10.1007/BF02296338

Kohles, J. C., Bligh, M. C., \& Carsten, M. K. (2013). The vision integration process: Applying Rogers' diffusion of innovations theory to leader-follower communications. Leadership, 9(4), 466-485. https://doi.org/10.1177/1742715012459784

Korschun, D., Bhattacharya, C. B., \& Swain, S. D. (2014). Corporate social responsibility, customer orientation, and the job performance of frontline employees. Journal of Marketing, 78(3), 20-37. https://doi.org/10.1509/jm.11.0245

Koufteros, X., Babbar, S., \& Kaighobadi, M. (2009). A paradigm for examining second-order factor models employing structural equation modeling. International Journal of Production Economics, 120(2), 633-652. https://doi.org/10.1016/j.ijpe.2009.04.010

Lebrun, A. M., Souchet, L., \& Bouchet, P. (2013). Social representations and brand positioning in the sporting goods market. European Sport Management Quarterly, 13(3), 358-379. https://doi.org/10.1080/16184742.2013.787539

Maltz, E., \& Schein, S. (2012). Cultivating shared value initiatives: A three Cs approach. Journal of Corporate Citizenship, (47), 55-74. 
McWilliams, A., \& Siegel, D. (2001). Corporate social responsibility: A theory of the firm perspective. Academy of Management Review, 26(1), 117-127. https://doi.org/10.5465/amr.2001.4011987

Nike+ Run Club. (n.d.). Seven truths: The Nike+ Run Club philosophy. https://www.nike.com/us/en_us/c/running/nike-run-club.

Porter, M. E., \& Kramer, M. R. (2011). The big idea: Creating shared value. Harvard Business Review, 89, 62-77.

Rich, B. L., Lepine, J. A., \& Crawford, E. R. (2010). Job engagement: Antecedents and effects on job performance. Academy of Management Journal, 53(3), 617-635. https://doi.org/10.5465/amj.2010.51468988

Sato, M., Jordan, J. S., \& Funk, D. C. (2015). Distance running events and life satisfaction: A longitudinal study. Journal of Sport Management, 29(4), 347-361. https://doi.org/10.1123/jsm.2013-0164

Schaufeli, W. B., Taris, T. W., \& Van Rhenen, W. (2008). Workaholism, burnout, and work engagement: three of a kind or three different kinds of employee well-being?. Applied Psychology, 57(2), 173-203. https://doi.org/10.1111/j.1464-0597.2007.00285.x

Schmitt, J., \& Renken, U. (2012). How to earn money by doing good! Shared value in the apparel industry. The Journal of Corporate Citizenship, 45, 79-103.

Shilbury, D., Sotiriadou, K. P., \& Green, B. C. (2008). Sport development. systems, policies and pathways: An introduction to the special issue. Sport Management Review, 11(3), 217-223. https://doi.org/10.1016/S1441-3523(08)70110-4

Slack, R. E., Corlett, S., \& Morris, R. (2015). Exploring employee engagement with (corporate) social responsibility: A social exchange perspective on organisational 
participation. Journal of Business Ethics, 127(3), 537-548. https://doi.org/10.1007/s10551$\underline{014-2057-3}$

Sudhir, K., \& Talukdar, D. (2004). Does store brand patronage improve store patronage. Review of Industrial Organization, 24(2), 143-160. https://doi.org/10.1023/B:REIO.0000033353.52208.ba

Swanson, S., \& Kent, A. (2017). Passion and pride in professional sports: Investigating the role of workplace emotion. Sport Management Review, 20(4), 352-364. https://doi.org/10.1016/j.smr.2016.10.004

Tanriverdi, H. (2006). Performance effects of information technology synergies in multibusiness firms. MIS Quarterly, 30(1) 57-77.

Vigoda-Gadot, E. (2007). Redrawing the boundaries of OCB? An empirical examination of compulsory extra-role behavior in the workplace. Journal of Business and Psychology, 21(3), 377-405. https://doi.org/10.1007/s10869-006-9034-5

Walker, M., \& Hills, S. (2017). Social program evaluations: Strategies and shared value. Sport \& Entertainment Review, 3, 65-71.

Walker, M., Hills, S., \& Heere, B. (2017). Evaluating a socially responsible employment program: Beneficiary impacts and stakeholder perceptions. Journal of Business Ethics, 143(1), 53-70. https://doi.org/10.1007/s10551-015-2801-3

Walzel, S., Robertson, J., \& Anagnostopoulos, C. (2018). Corporate social responsibility in professional team sports organizations: An integrative review. Journal of Sport Management, 32, 511-530. https://doi.org/10.1123/jsm.2017-0227 
Wang, T., Oh, L. B., Wang, K., \& Yuan, Y. (2013). User adoption and purchasing intention after free trial: an empirical study of mobile newspapers. Information Systems and E-Business Management, 11(2), 189-210. https://doi.org/10.1007/s10257-012-0197-5

Wójcik, P. (2016). How creating shared value differs from corporate social responsibility. Journal of Management and Business Administration, 24(2), 32-55. https://doi.org/10.7206/jmba.ce.2450-7814.168

Xanthopoulou, D., Bakker, A. B., Demerouti, E., \& Schaufeli, W. B. (2009). Reciprocal relationships between job resources, personal resources, and work engagement. Journal of Vocational Behavior, 74(3), 235-244. https://doi.org/10.1016/j.jvb.2008.11.003 
Table 1

A Description of Dimensions of Employee CSV Perception and Representative Quotations from Interviews

\begin{tabular}{|c|c|c|}
\hline Dimension & Definition & Representative Quotations \\
\hline \multirow[t]{2}{*}{ Sport value } & $\begin{array}{l}\text { The development of sport } \\
\text { in the process of value } \\
\text { creation (Shilbury et al., } \\
\text { 2008) }\end{array}$ & $\begin{array}{l}\text { "NRCGC not only led running activities but also taught them [participants] } \\
\text { necessary knowledge, such as injuries and types of running, that they should } \\
\text { know." }\end{array}$ \\
\hline & & "NRCGC promoted the running participation in Shanghai." \\
\hline \multirow[t]{2}{*}{ Social value } & $\begin{array}{l}\text { The promotion of common } \\
\text { good in society (Dembek et } \\
\text { al., 2016) }\end{array}$ & $\begin{array}{l}\text { "I think we are leading a healthy lifestyle through running. Participants would be } \\
\text { benefited by running with us." }\end{array}$ \\
\hline & & $\begin{array}{l}\text { "NRCGC provided participants a platform for interaction. To my knowledge, some } \\
\text { of them become good friends now." }\end{array}$ \\
\hline \multirow[t]{2}{*}{ Economic value } & $\begin{array}{l}\text { Revenues or productivity } \\
\text { increase for companies } \\
\text { (Dembek et al., 2016) }\end{array}$ & $\begin{array}{l}\text { "NRCGC raised people's passion in running, which then stimulated their demands } \\
\text { of running related products." }\end{array}$ \\
\hline & & $\begin{array}{l}\text { "It is understandable that Nike is making money through operating NRCGC. If we } \\
\text { cannot contribute to the revenue growth, we would not be maintained." }\end{array}$ \\
\hline
\end{tabular}


Table 2

EFA Results of Employee CSV Perception

\begin{tabular}{cccc}
\hline Item & Sport Value & Social Value & Economic Value \\
\hline CSV1 & .73 & - & - \\
CSV2 & .97 & - & - \\
CSV3 & .84 & - & - \\
CSV4 & - & .69 & - \\
CSV5 & - & .89 & - \\
CSV6 & - & .64 & - \\
CSV7 & - & - & .86 \\
CSV8 & - & - & .68 \\
CSV9 & - & - & .59 \\
Eigenvalue & 5.49 & 1.82 & 1.10 \\
\% of variance & 49.94 & 16.57 & 9.99 \\
Cronbach's $\boldsymbol{\alpha}$ & .89 & .80 & .75 \\
\hline
\end{tabular}

Note. $N=207 . \overline{C S V}=$ Employee CSV Perception Scale. The detailed information of the items is provided in Table 3. Factor loadings of $<.40$ are now shown in the table. 
Table 3

CFA Results of the Full Measurement Model

\begin{tabular}{llc}
\hline Label & \multicolumn{1}{c}{ Constructs/Items } & $\boldsymbol{\beta}$ \\
\hline & Sport value & \\
CSV1 & We attract more people to marathon. & .87 \\
CSV2 & People's running skills are improved through our service. & .91
\end{tabular}

CSV3 We popularize marathon in China. $\quad .89$

\section{Social value}

$.81 \quad .60$

CSV4 We lead a healthy lifestyle through running. $\quad .75$

CSV5 Participants made new friends after running with us. $\quad .86$

CSV6 People became more optimistic after running with us. $\quad .70$

Economic value

$.84 \quad .74$

CSV7 We help Nike attract more customers. $\quad .95$

CSV8 We help Nike increase sales of running shoes. 75

CSV9 We contribute to Nike's revenue growth. 60

CSV perception

$.84 \quad .68$

$\begin{array}{ll}\text { Sport value } & .70\end{array}$

$\begin{array}{ll}\text { Social value } & 95\end{array}$

$\begin{array}{ll}\text { Economic value } & .72\end{array}$

$\begin{array}{lll}\text { Vision integration } & .94 & .77\end{array}$

$\begin{array}{lll}\text { VI1 There is an agreement between leader and people at my } & .79\end{array}$

VI2 Knowing the organization's vision affects what I think is $\quad .90$ important when doing my job.

VI3 The organization's vision serves as a 'mental guideline' for how to do my job. be a successful employee. organization's vision. 
Table 3

CFA Results of the Full Measurement Model (Cont.)

\begin{tabular}{|c|c|c|c|c|}
\hline Label & Constructs/Items & $\boldsymbol{\beta}$ & $\mathbf{C R}$ & AVE \\
\hline & Work engagement & & .91 & .62 \\
\hline WE1 & At my work, I feel strong and vigorous. & .78 & & \\
\hline WE2 & At my work, I feel bursting with energy. & .87 & & \\
\hline WE3 & I am enthusiastic about my job. & .93 & & \\
\hline WE4 & My job inspires me. & .66 & & \\
\hline WE5 & When I get up in the morning, I feel like going to work. & .73 & & \\
\hline WE6 & I feel happy when I am working intensely. & .71 & & \\
\hline WE7 & I am proud of the work that I do. & .81 & & \\
\hline WE8 & I am immersed in my work. & .68 & & \\
\hline \multirow[t]{2}{*}{ WE9 } & I get carried away when I'm working. & .61 & & \\
\hline & In-role behavior & & .89 & .73 \\
\hline JP1 & I perform my task well with minimal time and effort. & .92 & & \\
\hline JP2 & I keep in mind the outcomes that I have to achieve & .95 & & \\
\hline \multirow[t]{2}{*}{ JP3 } & I appear in each NRCGC course on time. & .67 & & \\
\hline & Extra-role behavior & & .96 & .90 \\
\hline JP4 & I greet runners when they come into doors. & .95 & & \\
\hline JP5 & I chat/interact with runners before the start of courses. & .96 & & \\
\hline JP6 & I tell runners good things about our training courses. & .94 & & \\
\hline
\end{tabular}

Note. $N=181$. Items were measured on a 7-point Likert scale ranging from never (1) to always (7); CSV = Employee CSV perception scale; VI = Vision integration scale; WE = Work engagement scale; JP = Job performance scale. All standardized factor loadings were significant $(p<.01) ; \beta=$ Standard factor loading; CR $=$ Composite reliability coefficients; AVE = Average variance extracted. 
Table 4

Descriptive Statistics and Discriminant Validity Tests of the Measurement Model

\begin{tabular}{|c|c|c|c|c|c|c|c|c|}
\hline & Construct & 1 & 2 & 3 & 4 & 5 & 6 & 7 \\
\hline 1 & Sport value & .79 & & & & & & \\
\hline 2 & Social value & .46 & .60 & & & & & \\
\hline 3 & Economic value & .30 & .37 & .74 & & & & \\
\hline 4 & Vision integration & .35 & .43 & .37 & .77 & & & \\
\hline 5 & Work engagement & .14 & .33 & .15 & .31 & .62 & & \\
\hline 6 & In-role behavior & .08 & .14 & .11 & .17 & .12 & .73 & \\
\hline \multirow[t]{3}{*}{7} & Extra-role behavior & $.01^{\mathrm{a}}$ & $.02^{\mathrm{a}}$ & $.01^{\mathrm{a}}$ & $.02^{\mathrm{a}}$ & $.01^{\mathrm{a}}$ & $.14^{\mathrm{a}}$ & .90 \\
\hline & $M$ & 6.52 & 6.32 & 6.13 & 6.62 & 6.17 & 6.54 & 6.06 \\
\hline & $S D$ & .60 & .41 & .65 & .53 & .73 & .80 & 1.20 \\
\hline 1 & Sport value & - & & & & & & \\
\hline 2 & Social value & .73 & - & & & & & \\
\hline 3 & Economic value & .69 & .75 & - & & & & \\
\hline 4 & Vision integration & .62 & .78 & .67 & - & & & \\
\hline 5 & Work engagement & .51 & .63 & .47 & .62 & - & & \\
\hline 6 & In-role behavior & .33 & .43 & .38 & .51 & .56 & - & \\
\hline 7 & Extra-role behavior & .03 & .11 & .06 & .15 & .21 & .41 & - \\
\hline
\end{tabular}


Table 5

Model Comparisons for CSV Perception

\begin{tabular}{ccccccc}
\hline Models & $\boldsymbol{\chi}^{\mathbf{2}}$ & $\boldsymbol{d} \boldsymbol{f}$ & $\boldsymbol{\chi}^{\mathbf{2}} \boldsymbol{/} \boldsymbol{d} \boldsymbol{f}$ & CFI & RMSEA & SRMR \\
\hline M1 & 1330.76 & 401 & 3.32 & .82 & .11 & .08 \\
M2 & 960.86 & 396 & 2.43 & .86 & .09 & .10 \\
M3 & 616.83 & 376 & 1.64 & .95 & .07 & .06 \\
M4 & 629.89 & 384 & 1.64 & .94 & .07 & .06 \\
\hline
\end{tabular}

Note. $N=181 ; \mathrm{M} 1=$ One-factor model, $\mathrm{M} 2=$ Three-factor uncorrelated model, $\mathrm{M} 3=$ Three-factor correlated model, M4 = Second-order factor model; $\chi^{2}=$ Chi-square; $d f=$ Degree of Freedom; CFI $=$ Comparative Fit Index; RMSEA = Root Mean Square Error of Approximation; SRMR = Standardized Root Mean Square Residual. 


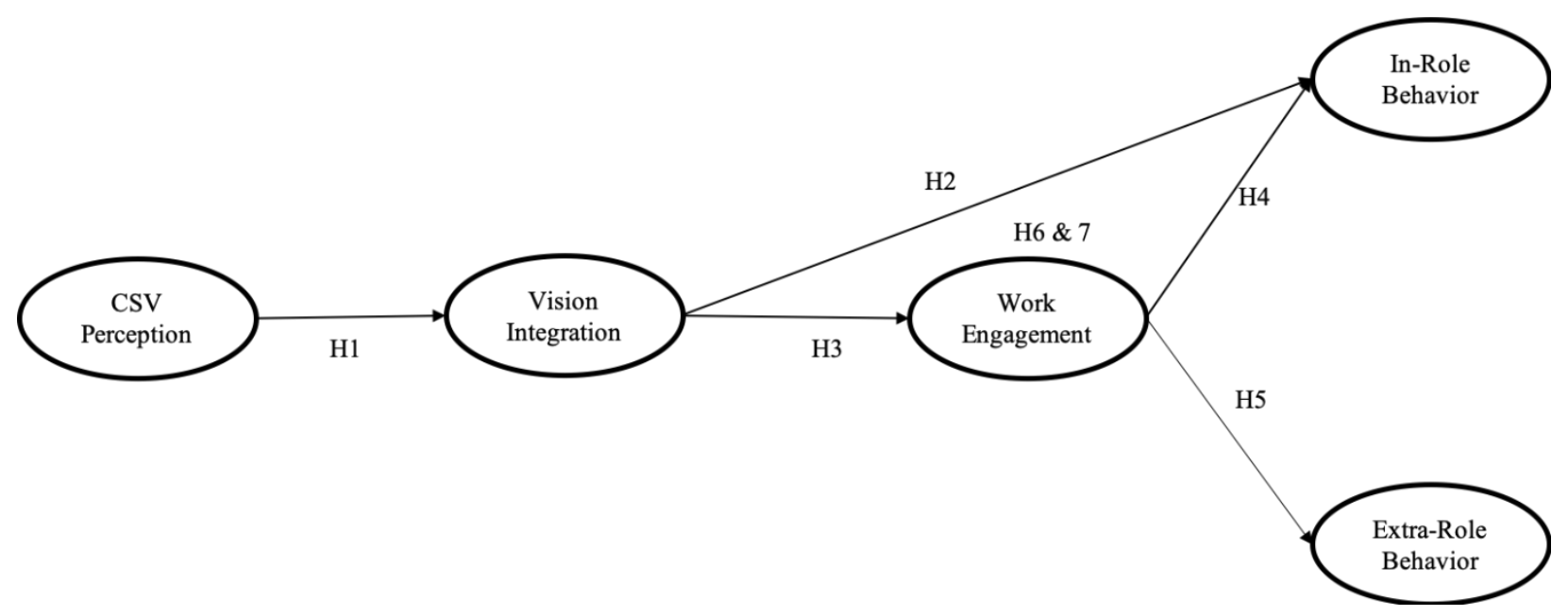

Figure 1. Hypothesized model. The circles represent latent variables. 


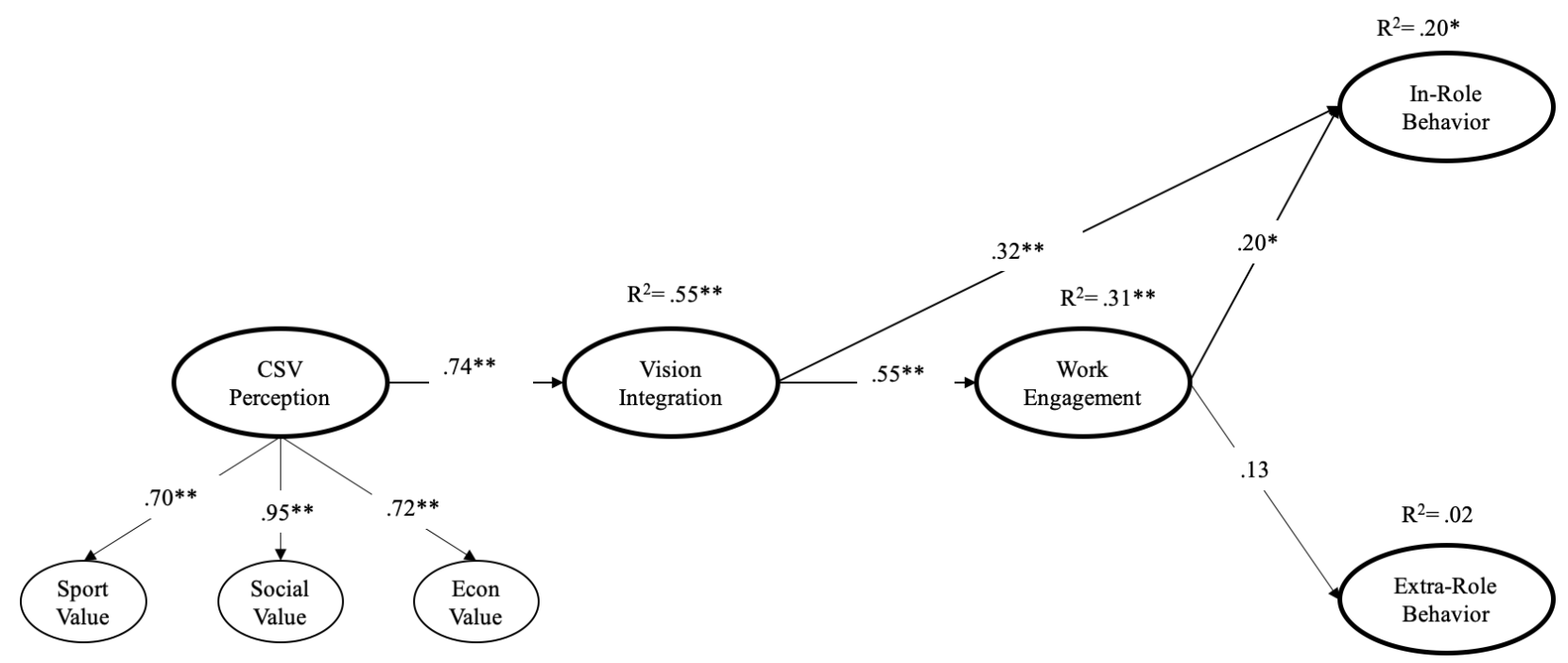

Figure 2. Results of structural model. The circles represent latent variables. $* p<.05, * * p<.01$. 